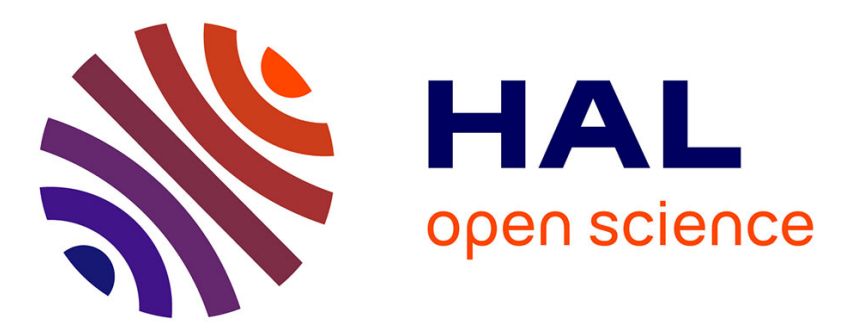

\title{
Structure of K-doped polyacetylene and its variations with annealing, studied by neutron diffraction
}

\author{
J.P. Aimé, M. Bertault, P. Delannoy, R.L. Elsenbaumer, G.G. Miller, M.
}

Schott

\section{To cite this version:}

J.P. Aimé, M. Bertault, P. Delannoy, R.L. Elsenbaumer, G.G. Miller, et al.. Structure of K-doped polyacetylene and its variations with annealing, studied by neutron diffraction. Journal de Physique Lettres, 1985, 46 (8), pp.379-385. 10.1051/jphyslet:01985004608037900 . jpa-00232527

\section{HAL Id: jpa-00232527 https://hal.science/jpa-00232527}

Submitted on 1 Jan 1985

HAL is a multi-disciplinary open access archive for the deposit and dissemination of scientific research documents, whether they are published or not. The documents may come from teaching and research institutions in France or abroad, or from public or private research centers.
L'archive ouverte pluridisciplinaire HAL, est destinée au dépôt et à la diffusion de documents scientifiques de niveau recherche, publiés ou non, émanant des établissements d'enseignement et de recherche français ou étrangers, des laboratoires publics ou privés. 
Classification

Physics Abstracts

$61.12-61.40 \mathrm{~K}$

\title{
Structure of K-doped polyacetylene and its variations with annealing, studied by neutron diffraction
}

\author{
J. P. Aimé $\left({ }^{*}\right)$, M. Bertault $\left({ }^{*}\right)$, P. Delannoy $\left({ }^{*}\right)$, R. L. Elsenbaumer $\left({ }^{* *}\right)$, G. G. Miller $\left({ }^{* *}\right)$ \\ and M. Schott (*) \\ (*) Groupe de Physique des Solides de l'E.N.S., Université Paris VII, 2, place Jussieu, \\ 75251 Paris Cedex 05, France \\ (**) Corporate Research, Allied Corporation, Morristown, N.J. 07960, U.S.A.
}

(Reçu le 9 janvier 1985, accepté le 21 février 1985)

\begin{abstract}
Résumé. - On a étudié par diffraction de neutrons sur poudre la structure du polyacétylène dopé au potassium à partir de l'état cis et les modifications structurales au recuit. Les spectres suggèrent une structure en canaux monoclinique de symétrie $P 2_{1 / m}$. Le recuit produit une légère contraction de la maille et une augmentation de l'ordre des chaînes de polymère.
\end{abstract}

\begin{abstract}
The structure of cis-polyacetylene doped with potassium and the structural effects of annealing were studied by powder neutron diffraction which is essentially sensitive to the chains. The spectra suggest a $\mathbf{P} 2_{1 / \mathrm{m}}$ monoclinic channel structure. Annealing produces a slight contraction of the unit cell and an increase in order of the polymeric chains.
\end{abstract}

\section{Introduction.}

It was found recently that annealing cis-polyacetylene $\left[(\mathrm{CH})_{x}\right]$ doped with potassium, at temperatures higher than $140{ }^{\circ} \mathrm{C}$, produces a large permanent increase in its room temperature d.c. conductivity by a factor of 5-10. The annealed films are remarkably stable even at temperatures as high as $200^{\circ} \mathrm{C}$ [1].

A somewhat smaller effect was observed on $\mathrm{Rb}$-doped samples, whereas $\mathrm{Li}$-doped, Na-doped and Cs-doped cis- $(\mathrm{CH})_{x}$ did not show any substantial conductivity increase upon annealing [1]. This behaviour of $n$-doped $(\mathrm{CH})_{x}$ contrasts sharply with that of the p-doped samples which degrade quickly and irreversibly upon even a modest increase of temperature [2].

Alkali-metal ions differ from p-dopants in two ways : they do not - with the possible exception of $\mathrm{Li}$ - attack the hydrocarbon chain; and their size is small. The latter property allowed Baughman to propose a structural model for n-doped polyacetylene, a channel structure of tetragonal symmetry [3] whereas it is generally accepted that p-doped material has an intercalated, layer, structure $[4,5]$. This proposal, however, is challenged by Flandrois [6] who proposes that alkali-metal-doped $(\mathrm{CH})_{x}$ is intercalated as well.

The aim of the present investigation, for which initial results are presented here, is twofold : to obtain a reliable model for the structure of n-doped $(\mathrm{CH})_{x}$; and to investigate the structural effects of annealing. 


\section{Experimental.}

The poor crystallinity of $(\mathrm{CH})_{x}$ films makes it difficult to obtain enough information in one diffraction experiment. However, as already pointed out by Hässlin et al. [5], the structure factors for neutrons and X-rays are very different, and therefore complementary information to X-ray diffraction can be obtained with neutrons. In addition, neutron scattering does not depend on $\sin \theta / \lambda$, hence structures at large $q$ are more easily observed. Results obtained from a series of measurements using neutron diffraction are reported here. Companion X-ray experiments are in progress.

Specifically, it is easy to show that in a K-doped cis-deuterated polyacetylene, $(\mathrm{CD})_{x}$ sample of composition $\left(\mathrm{CDK}_{0.17}\right)_{x}$, the maximum achievable doping level, the dopant ions contribute to $\sim 4 \%$ of the total neutron diffracting power, whereas they dominate the X-ray diffraction. In the experiments presented here, information about the polymer chain is predominantly obtained.

A $100 \mathrm{mg}$ sample of cis-(CD) $x$ was synthesized at $-78^{\circ} \mathrm{C}$ by the Shirakawa method. Deuteration is necessary to avoid the large incoherent scattering by $\mathrm{H}$ atoms, but is not expected to affect the structural properties. The sample was doped using vacuum-line techniques by contact with a solution of K-naphthalide in THF for two days at room temperature, then thoroughly rinsed with THF and dried under dynamic vacuum. This procedure is known to achieve maximum doping [1]. The doped film is golden brown.

Powder diffraction experiments were performed on the D1B diffractometer, equipped with a position sensitive detector, at ILL Grenoble, at $\lambda=2.523 \AA$.

Spectra of the same sample were taken :

A) before annealing;

B) after $15 \mathrm{~min}$ at $140^{\circ} \mathrm{C}$, and

C) after an additional $30 \mathrm{~min}$ at $180^{\circ} \mathrm{C}$. On similar samples, it was found that such an annealing yields maximum conductivity enhancement [1]. Spectra of the empty glass sample tube were also taken. All measurements were performed at room temperature.

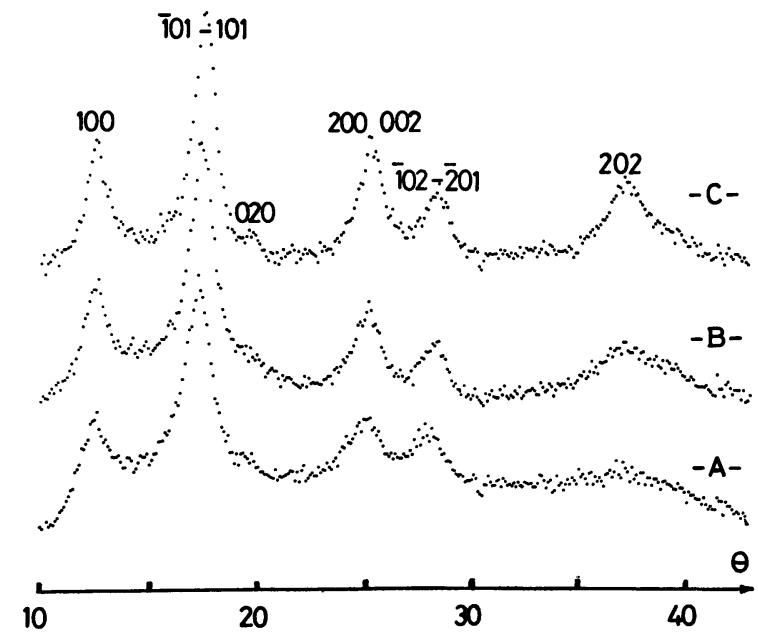

Fig. 1. - Experimental spectra as obtained from the normalized output of the position sensitive detector after subtraction of the scattering from the glass sample tube. Curves A), B) and C) correspond to the samples as described in $\S 2$. 


\section{Results and discussion.}

Typical spectra are shown on figure 1 . Scattering by the glass sample tube was subtracted. These data were smoothed by removal of the high frequency part of the Fourier transform. Figure 2 shows some significant parts of these corrected spectra. A more accurate line profile can be obtained after filtering; this is of some importance since, as we shall see, several lines are, in fact, groups of overlapping lines. Peaks were assumed to be Gaussian, and their position and width were calculated by least-square fits. Figure 3 shows an example of such a fit, on the unfiltered experimental results, around $\theta=170^{\circ}$.

Upon annealing, all lines shift to larger $q$ values. Changes of profiles and intensities are also observed, particularly at high $q$ values.
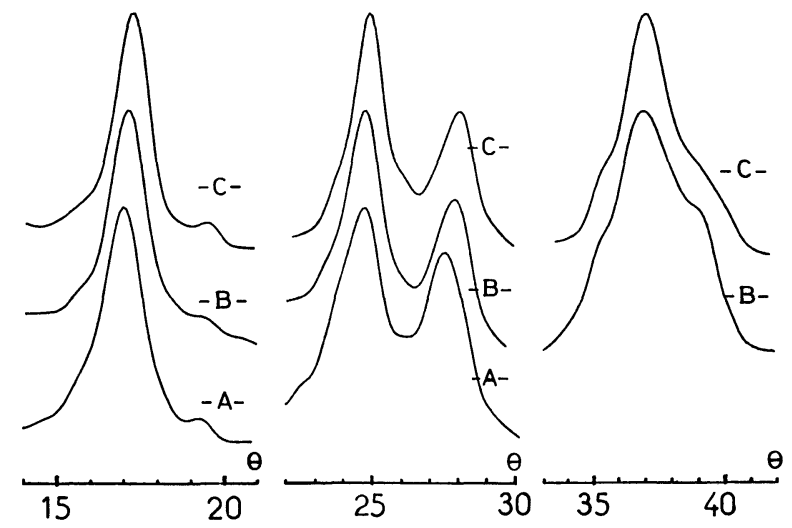

Fig. 2. - Regions of the spectra after filtering. (1) Around $\theta=17^{\circ}$, lines (101), (020), etc...; (2) Around $\theta=26^{\circ}$, lines (200), (102); (3) Around $\theta=37^{\circ}$, lines (202), (300), etc...

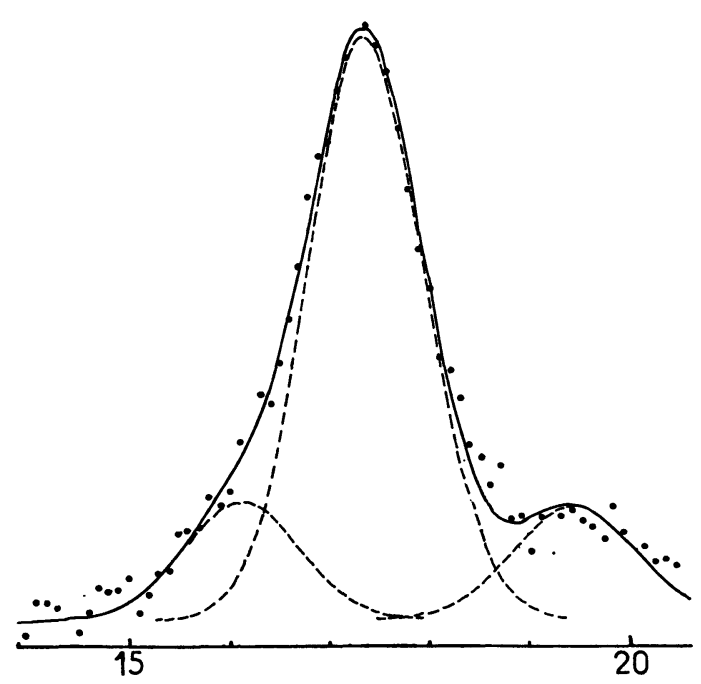

Fig. 3. - Gaussian fit of the region around $\theta=17^{\circ}$. Dots are experimental values. Dashed curves are 3 Gaussians and the solid curve is their sum. In order of increasing $\theta$, the three Gaussians correspond to (011) and (110); (101) and (101); and (020). The first line, not being accurately enough positioned by the fit, was not used in the refinements. 
3. 1 STRUCTURE OF THE n-DOPED PHASE. - Figure 1 shows that annealing only produces minor structural changes, so that it is meaningful to discuss the structure " of the n-doped phase ". Changes due to annealing will be further discussed below.

When the present data are used to compute a tetragonal cell, poor agreement is obtained. As seen in figure 2, Bragg peaks which should be unique in such a cell are in fact composite (for instance (200) and (002), or $(\overline{102})$ and $(20 \overline{1})$ ). Doublets are observed as required by a monoclinic cell which represents a slight distortion of the proposed tetragonal one [3]. Our spectra definitely do not agree with the proposed intercalated cell [6]. For instance, lattice plane spacings larger than $\sim 6 \AA$ are absent. On the contrary, only modifications of the proposed channel structure are needed.

Table I shows the results of different refinements. The line at $\theta=37.45^{\circ}$ in case $C$ ) which we index as (202) - with shoulders being $(\overline{202})$ and (300) - cannot be precisely located before annealing. Its introduction into the refinement makes the unit cell slightly smaller and farther from tetragonal. Note also that the $b$ parameter is calculated using a single weak line assigned to (020) at $\theta \sim 19.5^{\circ}$ by comparison with X-ray studies [7]. Preliminary structure factor calculations indicate that the contribution of $\mathrm{C}$ and $\mathrm{D}$ atoms to the $(020)$ intensity is negligible for all chain setting angles which leave enough room to place the $\mathrm{K}$ ions. The intensity is essentially due to the $\mathrm{K}$ atoms ; this explains why the $(020)$ line is much less intense in neutron scattering than in X-ray scattering. The repeat distance of the $\mathrm{K}$ ions in their channels is not necessarily commensurate to that of the polymer chains along $b$ (the system has no precise stoichiometry). In other words, the system may conceivably have two non-commensurate $b$ parameters. The present data do not allow to discuss this problem : order extends only over distances of $\sim 100 \AA$, and we have no proof of perfect ordering of the $\mathrm{K}$ ions. For these reasons, and because overlapping lines cannot be positioned precisely, an accurate determination of the unit cell parameters should await further data.

Table I. - Unit cell parameters.

$\begin{array}{lccccl} & a & b\left(^{*}\right) & c & \beta & \\ \text { a) Before annealing } & 5.98 & 7.63 & 5.96 & 91.7 & \text { Without (202) } \\ \text { b) Annealed at } 140^{\circ} \mathrm{C} & 5.98 & & 5.94 & 91.0 & \\ \text { c) Annealed at } 180^{\circ} \mathrm{C} & 5.94 & 7.56 & 5.91 & 91.0 & \text { With (202) } \\ \text { d) Annealed at } 180^{\circ} \mathrm{C} & 5.94 & 7.56 & 5.93 & 90.8 & \text { Without (202) }\end{array}$

$\left(^{*}\right)$ For the definition of $b$, see text.

Due to the symmetry of the polymer chain. a tetragonal cell must be non-primitive. Within a monoclinic lattice, a primitive cell is possible, so the indexations given here can be the true ones. Observation of (101) and (101) peaks suggests that the glide plane is in a general direction, compatible with our proposal of space group $\mathrm{P} 2_{1 / \mathrm{m}}$.

In this space group, the chains occupy two distinct sites, not related by symmetry elements of the factor group (Fig. 4). The chain setting angles are arbitrary. A preliminary attempt at estimating them from the measured structure factors has been made, assuming that the carbon atoms along a chain are equidistant, following the prediction of theoretical calculations [8]; it suggests a best fit with angles 10 to $20^{\circ}$. A satisfactory close packing with little overlap of van der Waals spheres, i.e. little chain distortion, occurs for instance by locating the $\mathrm{K}$ ions at positions $\left(x, \frac{1}{4}, z\right)$ and $\left(x, \frac{3}{4}, z\right)$, as required by the proposed $\mathrm{P} 2_{1 / \mathrm{m}}$ structure with $x$ and $z \# \frac{1}{2}$. Note however that the present data do not allow to locate precisely the $\mathrm{K}$ atoms, nor to determine their degree of order. Disorder K atoms (in their channels) would be compatible with an overall $\mathrm{P} 2_{1 / \mathrm{m}}$ symmetry. If the $\mathrm{K}$ ions are neither disordered along $b$, nor placed as proposed above, then an overall structure 

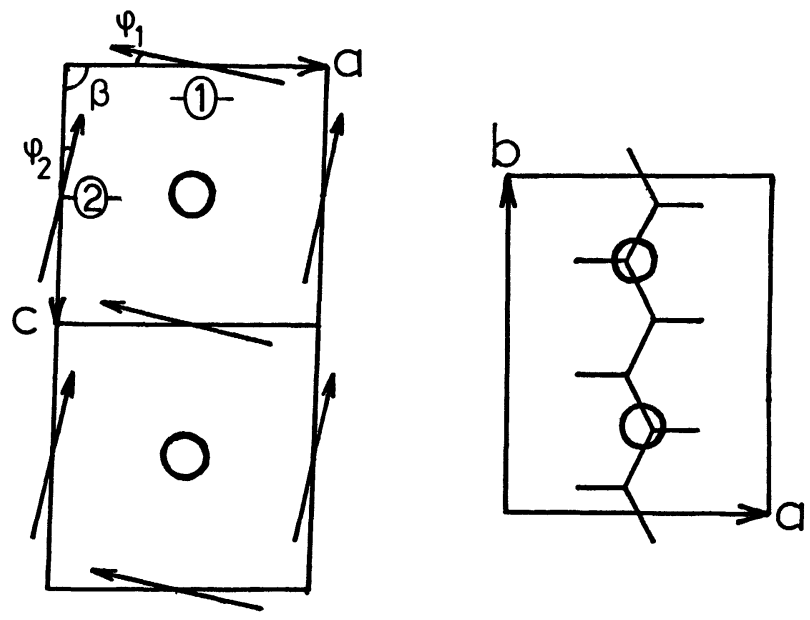

Fig. 4. - Proposed unit cell. Arrows indicate (CD) $)_{x}$ chains, on two non-equivalent sites labelled 1 and 2 with setting angles $\varphi_{1}$ and $\varphi_{2}$. Circles are positions for $\mathrm{K}^{+}$ions compatible with the $\mathrm{P} 2_{1 / \mathrm{m}}$ group. For simplicity of the drawing, $x=z=\frac{1}{2}$ is assumed on the figure, but this is not necessarily so.

of lower symmetry and possibly a non-primitive cell would follow. Further X-ray and neutron measurements now in progress should lead to better accuracy.

3.2 Changes UPON ANNEALING. - Upon annealing there is a general contraction of the unit cell at least in the equatorial plane (perpendicular to the chains average direction) already seen by Baughman et al. [3]. In addition, there is a large increase in scattered intensity at large angles (Fig. 1) and individual lines tend to become narrower. This can be expressed as an increase in " coherence length " although the determination of this length should take into account the probable paracrystalline nature of the material, and might be difficult to implement owing in practice to the overlapping of several lines. A coherence length, defined in the usual way by the Scherrer formula, would increase from $\sim 50 \AA$ to more than $70 \AA$ in the equatorial plane, upon annealing.

A recurring question in all investigations of $(\mathrm{CH})_{x}$ doping is that of doping heterogeneities. Since the spectrum can be completely accounted for using a single structure, and since no line corresponding to the known structure of undoped cis- and trans- $(\mathrm{CH})_{x}$ is observed, the sample is homogeneously doped on a scale $\sim 100 \AA$ over at least $80 \%$ of its " crystalline » volume. The size of crystalline units $(\sim 100 \AA)$ does not seem compatible with a strong radial $\mathrm{K}$ ion concentration variation in the fibrils which diameter is at most $\lesssim 500 \AA:$ if they penetrate the fibrils, then they are distributed fairly homogeneously within them.

The observed changes can be understood as an increase in " crystallinity ". For instance, the existence of static fluctuations of atomic positions of mean square value $\left\langle\boldsymbol{u}^{2}\right\rangle$, which can be related to static fluctuations of bond lengths, bond angles (a limiting case would be a kink), or of the setting angles, or to disorder among the potassium ions, will reduce the intensities by a factor $\exp -Q^{2}\left\langle u^{2}\right\rangle$. Better order means a preferential increase of large $Q$ Bragg peaks. This is to be related to the large increase of line (202) upon annealing (Table II and Fig. 1). Neutron scattering is due essentially to the polymer chain atoms (with the exception of $(020)$ line) and the effect of $\mathrm{K}$ ion ordering is therefore felt mainly indirectly. It may be that a better ordering of the $\mathrm{K}$ ions allows a slightly more compact structure, hence a small contraction of the unit cell. The change of some structure factors (Table II) may indicate that the polymer chain setting angles change 
Table II. - Measured intensities of some Bragg lines (referred to $I(101)=1$ on each spectrum).

a) Before annealing

b) Annealed at $140^{\circ} \mathrm{C}$

c) Annealed at $180^{\circ} \mathrm{C}$
0.32

0.37

0.49
0.24

0.29
(202)

$\sim 0$

0.23

0.29

simultaneously. As made clear by the indexation of the observed lines the present data give informations about the order in the plane perpendicular to the chain direction.

The conductivity increase can be due to several factors. Here we have shown that order in the " crystalline » regions of the fibrils improves upon annealing. The two phenomena may, however, be more indirectly connected ; for example, the better order may be related to the disappearance of remaining isolated short cis-segments as suggested in reference [1], which would be adverse to carrier transport; or to ordering of the $\mathrm{K}^{+}$ions as just mentioned and/or reorientation and straightening of polymer chains, causing a change in band structure and in the role played by the potassium ions in carrier transport (the variation of EPR linewidth may be related to an increase of charge density on $\mathrm{K}^{+}$, hence of spin-orbit coupling [9]).

3. 3 SOME REMARKS ON STRUCTURAL CHANGES UPON DOPING. - An intriguing fact is that $\mathrm{n}$-doping does not irreversibly degrade the polyacetylene structure (as apparently p-doping does) : K-doped cis- $(\mathrm{CH})_{x}$ can be quantitatively de-doped chemically, the resulting product is the usual trans$(\mathrm{CH})_{x}$, with spectroscopic properties (absorption and resonance Raman) indicative of a " high quality " polymer - in fact, of higher quality than nearly any thermally isomerized film [10]. The structural evolution on doping will not be discussed here, since it may proceed through a series of stages [7]. The differences between the undoped and doped structures are fairly large. We wish to point out that the proposed tetragonal cell [3] implies that on doping, at least one out of the following occurs : rotation of half of the chains by $180^{\circ}$, translation along their axis, or disorder in their position along their axis. The proposed monoclinic structure implies that none of these need occur.

\section{Conclusion.}

Neutron scattering data on K-doped $(C D)_{x}$ films give preferentially information on the polymer chains and therefore complement X-ray scattering data. More accurate measurements reveal that the unit cell symmetry is not as high as reported previously [3]. On the basis of the present data, we propose a monoclinic primitive unit cell, space group $\mathrm{P} 2_{1 / \mathrm{m}}$, a slight distortion of a tetragonal cell. We hope with further data to be able to position the polymer chains and the potassium ions within the cell. A preliminary calculation yields a polymer setting angle of about 10 to $20^{\circ}$.

The annealing which produces a large conductivity increase in samples doped from the cisform [1] also produces noticeable changes in the neutron diffraction spectra. Besides a slight contraction of the unit cell, the order is much improved in the annealed samples, possibly indicating that the chains are slightly reoriented.

Further data and a more detailed discussion will be presented in a forthcoming publication.

\section{Acknowledgments.}

We are grateful to R. H. Beughman and J. P. Pouget for their interest in this work and useful discussions and to $\mathbf{M}$. Heyman for help with the data treatment. This research was made possible by time allocation given to us on the D1B powder diffractometer at ILL, Grenoble. 


\section{References}

[1] Eckhardt, H., Delannoy, P., Miller, G. G., Murthy, N. S. and Baughman, R. H., 38th Calorimetry Conference Proceedings, Williamsburg, VA, Sept. 1983.

Elsenbaumer, R., Delannoy, P., Miller, G. G., Forbes, C. F., Murthy, N. S., Eckhardt, H. and BAUGHMAN, R. H., to be published.

[2] Rolland, M., Lefrant, S., Aldissi, M., Bernier, P., Rzedka, E., Schúe, F., J. Electron. Mater. 10 (1981) 619.

[3] Baughman, R. H., Murthy, N. S. and Miller, G. G., J. Chem. Phys. 79 (1983) 515.

[4] Baughman, R. H., Murthy, N. S., Miller, G. G., Shacklette, L. W., J. Chem. Phys. 79 (1983) 1065.

[5] Hasslin, H. W., Riekel, C., Menke, K. and Roth, S., Makromol. Chem. 185 (1984) 397.

[6] Flandrois, S., Hauw, C. and François, B., J. Physique Colloq. 44 (1983) C3-523.

[7] Baughman, R. H., Shacklette, L. W., Murthy, N. S., Miller, G. G. and Elsenbaumer, R. L., Proceedings of ICSM 84, Abano Terme, Italy; to appear in Mol. Cryst. Liq. Cryst. See also, Shacklette, L. W., Murthy, N. S. and Baughman, R. H., ibid.

[8] Bredas, J. L., Chance, R. R., Silbey, R., J. Phys. Chem. 85 (1981) 756.

Karpfen, A. and Petkov, J., Theor. Chem. Acta 53 (1979) 65.

[9] Forbes, C. E., Delannoy, P., Miller, G. G., Murthy, N. S., Eckhardt, H., Elsenbaumer, R. L. and Baughman, R. H., to be published.

[10] Eckhardt, H. and Steinhauser, S. W., Mol. Cryst. Liq. Cryst. 105 (1984) 219.

Berrehar, J., Fave, J. L., Lapersonne-Meyer, C., Schott, M. and Eckhardt, H., Proceedings of ICSM 84, Abano Terme, Italy; to appear in Mol. Cryst. Liq. Cryst. 